\title{
ANKOS Publisher Application System and Its Impact on the e-Resource Evaluation Process
}

\author{
Burcu Bulut a,*, Handan Uğur b , Gültekin Gürdal ${ }^{\text {c }}$, Illkay Holt d , Sami Çukadar ${ }^{\text {e, }}$ \\ Emre H. Akbayrak ${ }^{\text {a }}$, Mustafa K. Çelebi ${ }^{\mathrm{f}}$ \\ a Middle East Technical University, Universiteler Mahallesi, Dumlupinar Bulvari No:1, Ankara 06800, Turkey \\ b Istanbul Technical University, Ayazaga Kampusu, Istanbul 34469, Turkey \\ c Izmir Institute of Technology, Gulbahce Kampusu-Urla, Izmir 35430, Turkey \\ d Ozyegin University, Kusbakisi Cad. No:2, Istanbul 34662, Turkey \\ e Istanbul Bilgi University, Eski Silahtaraga Elektrik Santrali, Kazim Karabekir Cad. No: 2/13, Istanbul 34060, Turkey \\ f Cukurova University, Balcali, Adana 01330, Turkey
}

\section{A R T I C L E I N F O}

Available online 20 February 2013

\section{Keywords:}

Anatolian University Libraries Consortium (ANKOS)

Electronic resource management systems e-Resources

e-Resource evaluation process

Online evaluation systems

\begin{abstract}
A B S T R A C T
The Publisher Application System (PAS) is a Web-based archiving and online evaluation system developed by the Database Evaluation Group (DEG), one of the working groups formed within the Anatolian University Libraries Consortium (ANKOS). The DEG was formed in 2008 to inquire and evaluate e-resources suited to the needs of the consortium; to follow up similar consortial activities worldwide as well as developments in connection with the scientific publishing industry; and to determine, implement, and improve pricing models in accordance with the prevailing economic, legal, and academic system. Development of the PAS was essential to ensure standardization and sustainability towards a more detailed and effective analysis of e-resources qualifying for evaluation by ANKOS. The PAS played an important part not only in establishing and defining the workflow of the DEG, but also in creating an archive of both the e-resources submitted to the consortium and the applicant publishers/agents submitting these resources. This article outlines the process that started with the foundation of the DEG through the formation of the PAS as well as the present setup of the system. It is also hoped that this case study will have a positive contribution to the processes being followed by the persons and the groups engaged in similar activities.
\end{abstract}

(C) 2013 Elsevier Inc. All rights reserved.

\section{Introduction}

In this age, commonly recognized as the age of information, speed and technology, fast and easy access to reliable information independent from restrictions of time and location has become paramount. The transition of information from printed form to electronic form has become widespread and the current state of technology presents virtually unlimited possibilities for access to information. The Internet has created a new universal realm for the sharing of information and for collaboration and trade. Consortial activities, therefore, have gained importance, and from the 2000s onwards, which marked the start of electronic journal publishing, major libraries throughout the world have come together to form consortia in order to make user access to information simpler and cheaper. ANKOS, founded in 2000 in Turkey with this exact same purpose, included 12 initial member institutions

\footnotetext{
* Correspoding author.

E-mail addresses: bketen@metu.edu.tr (B. Bulut), ugurha@itu.edu.tr (H. Uğur), gultekingurdal@iyte.edu.tr (G. Gürdal), Ilkay.Holt@ozyegin.edu.tr (İ. Holt), sami.cukadar@bilgi.edu.tr (S. Çukadar), akbayrak@metu.edu.tr (E.H. Akbayrak), celebi@cu.edu.tr (M.K. Çelebi).
}

acquiring a joint subscription to three databases. ANKOS today has evolved into a consortium with an international reputation, an industry-wide professional association, and a countrywide community of volunteers with a total of 1773 individual agreements for 83 databases provided by over 60 publishers. It has a membership roster of 155 universities and research institutions as well as a workforce of 45 volunteers ${ }^{1}$ (www.ankos.gen.tr). Figure 1 shows a detailed organizational structure of ANKOS, managed by a Steering Committee (SC) of seven, consisting of a chairperson and six members.

Having placed great importance on international cooperation since its foundation, ANKOS is a founding member of the Southern European Libraries Link (SELL), which was established in 2001 and has Portugal, Spain, Italy and Greece among its members.

Founded in the United States in 1999 with the aim of breaking commercial publishers' monopoly, preventing an increase in scientific journal prices, and creating a competitive environment, the Scholarly Publishing and Academic Resources Coalition (SPARC) opened their European branch in 2002. In the same year, ANKOS became a member

\footnotetext{
${ }^{1}$ As of February 2012.
} 


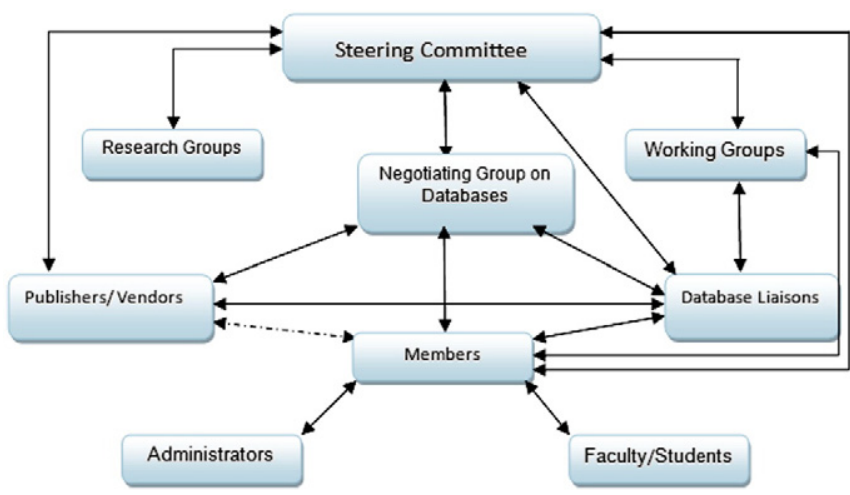

Figure 1. Organizational structure of ANKOS.

of SPARC Europe, thereby lending support to the initiative. The goal of open access and open archives, instigated by SPARC, became one of the most widely discussed topics within publishing and librarianship circles the world over and is further gaining popularity. ANKOS is also a member of the International Coalition of Library Consortia (ICOLC) and of Counting Online Usage of Networked Electronic Resources (COUNTER).

As of 2012, ANKOS included five working groups (WG) and a research group (RG) within its organization. These are as follows:

- License Agreements Group (WG)

- Public Relations Group (WG)

- Usage Statistics Group (WG)

- Database Evaluation Group (WG)

- Open Access and Institutional Archives Group (WG)

- Collaboration Research Group (RG)

ANKOS has been chosen as a subject for a number of scientific works in ANKOS's home country and abroad for the processes the consortium has so far established (Akbaytürk, 2003a, 2003b; Cimen, Tuglu, Manyas, Celikbas, \& Celikbas, 2009; Cukadar, Tuglu, \& Gurdal, 2012; Erdogan, 2009; Erdogan \& Karasozen, 2006; Karasözen, 2002; Karasozen, Kaygusuz, \& Ozen, 2007; Karasozen \& Lindley, 2004; Lindley, 2004; Özen, 2007; Toplu, 2009). Placing continuous progress, innovation, and productivity at the core of its activities, ANKOS aims to set an example to persons and institutions alike who may wish to engage in similar activities in the future.

\section{Database Evaluation Group}

As the abundance of e-resources increases at a great pace, there emerged a need to form a group to ensure efficient evaluation of the e-resources that are considered within the scope of ANKOS, to employ multiple monitoring mechanisms during the evaluation process, and to provide a standard and systematic approach. The decision to form the Database Evaluation Group, DEG, was made on May 14, 2008, in a meeting held at the Izmir Institute of Technology with the participation of librarians selected and invited by the Chairman of ANKOS. The first meeting of the group, following the selection of its members, was held in July 2008 at the Middle East Technical University in Ankara. The DEG was formed with the participation of librarians ${ }^{2}$ from eight

\footnotetext{
${ }^{2}$ Emre H. AKBAYRAK (Orta Doğu Teknik Üniversitesi, akbayrak@metu.edu.tr). Mustafa Kemal ÇELEBİ (Çukurova Üniversitesi, celebi@cu.edu.tr).

Sami ÇUKADAR (İstanbul Bilgi Üniversitesi, sami.cukadar@bilgi.edu.tr). Güssün GÜNEŞ (Koç Üniversitesi, ggunes@ku.edu.tr) - left the group in 2010.

Gültekin GÜRDAL (İzmir Yüksek Teknoloji Üniversitesi, gultekingurdal@iyte.edu.tr).

İlkay HOLT (Özyeğin Üniversitesi, Ilkay.Holt@ozyegin.edu.tr).

Burcu BULUT (Orta Doğu Teknik Üniversitesi, bketen@metu.edu.tr).

Eda KÖSE (Hacettepe Üniversitesi, edakose@hacettepe.edu.tr) - joined the group in 2010. Handan UĞUR (İstanbul Teknik Üniversitesi, ugurha@itu.edu.tr).
}

different universities of varying sizes, all of which are located in different cities and are active in their respective fields. These librarians in the DEG were selected from among professionals who are specialists in different subject areas.

The mission of the DEG is to provide support for ANKOS members to improve their collections by subjecting those e-resources qualifying for consideration by the consortium to an evaluation process, in interaction with authorized people, groups and committees; and to provide support for the consortium members so that they can enable e-resources by way of economical acquisition/subscription in line with institutional requirements and can manage their budgets efficiently. In the context of this mission statement, the group's responsibilities were determined as follows:

- To determine the criteria for selection of e-resources

- To determine the resource requirements of university libraries in Turkey

- To define and develop pricing models suitable for Turkey

- To provide information to publishers/vendors on the structure and set up of university libraries in Turkey

- To locate new e-resources

- To follow developments in the field of e-resources

- To collect proposals for new e-resources

- To evaluate and negotiate on the e-resource proposals collected

- To share the resource proposals being evaluated with ANKOS members

- To form an information pool for e-resources being evaluated

- To follow and assess similar consortium activities worldwide

- To represent Turkey in similar consortium activities worldwide.

Guided by the ANKOS Chairman during the initial phase (2008-2011) and then by a designated member of the Steering Committee (2012), DEG performed its activities in cooperation with the License Agreements Group (LAG) and Database Liaisons (DL).

\section{3. e-Resource Evaluation Process}

The criteria applied to the evaluation of e-resources are based on the shared knowledge and experience accumulated since the formation of ANKOS as well as on scientific work. Parameters taken into consideration while evaluating e-resources in various formats are increasing in number and diversity almost daily.

The e-resource evaluation process consists of six stages. The preliminary stage of the process involves determination of the e-resources that will be taken into consideration. These resources may be products directly entered into the system by publishers as well as those determined as a result of suggestions from ANKOS member institutions, DEG members, Database Liaisons (DL), or from the members of the Steering Committee. In case of a decision to evaluate the e-resource in accordance with the received suggestions, the relevant publisher/ agent is contacted and instructed to register the product into the system. Below is a brief summary outlining the evaluation stages of e-resources.

\subsection{Stage 1: The Entry of Database Information into the System}

- Database is entered into PAS. After the publisher/agent enters the resource into the system and confirms the entry, the completed form and any documents attached thereto are added to an e-mail which is then automatically sent to all DEG members whose names are already registered in the system.

- A DEG member is assigned to each new product entered into the PAS. The assignment is carried out over the system by the group coordinator, also a member of the Steering Committee. When the assignment is complete, the system sends out an automated information message to all group members. 
- The DEG member assigned to the product performs a preliminary evaluation. During the evaluation, the Publisher Application Form (PAF) is checked to ensure that it is completed properly by the publisher/agent and that all documents forming the basis of the evaluation have been provided. The relevant DEG member then informs the other group members of the status of the PAF through the system, after which the evaluation process begins. If a problem is detected, the publisher/ agent is contacted via e-mail. The product is then evaluated once more until incomplete entries are properly completed.

\subsection{Stage 2: Preliminary Evaluation of the Database}

Documents included in the PAF are reviewed and a decision is made about whether the product in question is to be considered by the consortium. The review is carried out with reference to policies already set out by ANKOS. ${ }^{3}$ Information related to opening a trial access for the product is considered. It is a general preference, with the exception of very special circumstances, that products for which a trial access is not opened should not be accepted for the evaluation process.

\subsection{Stage 3: Opening Trial Access for the Database}

All correspondence concerning a product ${ }^{4}$ found to be suitable for opening for trial access as a result of the preliminary evaluation is carried out by the assigned DEG member. Following completion of the necessary technical reviews, an announcement in relation to the trial access is drafted and sent out to all ANKOS members included on the mailing list. Products opened for trial access are also announced on the ANKOS Page for Trial Databases ${ }^{5}$ and archived there. Information related to trial access is recorded in the PAS. Furthermore, usage statistics obtained in the trial access are shared with ANKOS members and are recorded in the PAS. After the usage statistics of the trial access are received by the relevant DEG member, the detailed evaluation stage begins. Usage statistics are ideally shared with all ANKOS members included in the ANKOS mailing list along with the decision reached as a result of the detailed evaluation process and price information. When price negotiations take longer than expected, usage statistics may, as a rare occurrence, be shared with members before the completion of the detailed evaluation process.

\subsection{Stage 4: Detailed Evaluation}

\subsubsection{Compiling and Synthesizing Data}

All information entered into the system by the publisher/agent and the trial access usage statistics are compiled and synthesized. In the synthesizing stage, the product is examined in terms of the use of e-resource management tools, costs, and the probable impact on databases with e-journal content. Subscriber institutions outside of the consortium are determined to inquire from them past information related to the database that would help in the general evaluation. Within the general evaluation,

- A requirement analysis is performed. Profiles of the ANKOS member institutions (target users analysis), requests from members, etc., are taken into consideration.

\footnotetext{
${ }^{3}$ ANKOS adopts different policies in different times. For example, priority in 2010 was placed on evaluation of databases produced by publishers of a non-commercial nature having subscribers in Turkey. In 2011, it was decided to not evaluate e-books with very large collections under the scope of the Consortium.

4 Throughout the year, new product offers were evaluated by the DEG members, and the existing license renewal offers were handled by the relevant Database Liaison and SC member. Information related to the products entered into the System was either shared with the Database Liaisons by the SC members who are capable of logging in the system with their own username and password, or with the relevant SC member or Database Liaisons by a DEG member. It is still being discussed as to how this will work in 2012.

${ }^{5}$ http://www.ankos.gen.tr/genel/denemeveritabanlari_2011.
}

- Country specific conditions, legal and economic conditions, and prevailing policies are taken into consideration.

- Developments in the world are monitored. The status of the product being evaluated within other, similar consortial work, its references, assessments found in professional literature, etc., are taken into account.

- Reliability is determined. Assessments are carried out and opinions sought concerning both the product on offer and the relevant publisher's/agent's standing in the market.

\subsubsection{Drafting a Detailed Evaluation}

A detailed evaluation of the product is conducted with reference to the criteria included in the PAF during the general evaluation.

3.4.2.1. Evaluating the Company. The category (commercial, society, aggregator) of the company submitting the offer is defined. The representation status of the company in Turkey is investigated. These considerations have a bearing on the negotiation stage with the category of the company and the existence of a representative in Turkey having a direct impact on the communication process.

3.4.2.2. Evaluating the Product. Numerous criteria, such as the type of content, scope, publishing lists, references in Turkey and abroad, interface and platform specifications, compatibility with different platforms/ tools (e.g., federated search, discovery tools), indexing features, archiving policies, linking properties, access conditions, updating frequency, feature to provide MARC records, browser compatibility, language and training support, restrictions, reference management tools, etc., are examined thoroughly, and the scope of the product as well as possibilities and technical features it presents are reviewed in detail.

3.4.2.3. Evaluation in Relation to Pricing. This stage will determine the methods to be implemented in relation to how the negotiation will be conducted, such as the pricing model, annual price increases, list prices, the ANKOS proposal, exchange rates/fluctuating parities, obligation to continue with the existing subscriptions, DDP practices, and payment terms.

3.4.2.4. Evaluation in Relation to Usage. This step provides information such as whether usage statistics are provided, whether the product is COUNTER-compatible, the designation of the party to provide the statistics (publisher or the institution) and the frequency of doing so, and whether or not collected statistics are provided. This information is essential to unit cost analyses performed during the evaluation stage and reflects ANKOS members' interest in the product.

3.4.2.5. Evaluation of Documentation. A check is made to determine whether an exclusive agent certificate/Apostille (stamp) is provided. Documentation such as the user manual (Turkish-English), a tutorial (Turkish-English), the brochure (Turkish-English) as well as the format of the documents provided (printed/electronic), the provider of the documentation (publisher/vendor),and license agreement ${ }^{6}$ are important as they will determine the payment process, enable an examination of legal considerations, and provide an indication of the services aimed at the end-user.

The objective at the stage of the detailed evaluation is to achieve successful agreements on par with other consortia in the world and continue with the best possible conditions during license renewals and to achieve better and fairer conditions for all members.

\footnotetext{
${ }^{6}$ License agreements are subjected to detailed evaluation by the ANKOS LAG, and a decision is taken on the basis of the Group's opinion.
} 


\subsubsection{Interpretation}

At the conclusion of the evaluation work, all findings obtained by receiving the opinions of the subject matter experts within DEG as well as relevant academicians and colleagues in various institutions are brought together and interpreted. This is followed by the decision stage.

\subsection{Stage 5: Decision}

Detailed evaluation reviews performed by the DEG member assigned to the e-resource are shared on the system. Afterwards, other DEG members share their opinions and remarks. Additional discussions, inquiries, and further sharing of information take place, again by way of the system, and then a joint decision is taken. Price negotiations, in the light of the collected opinions, are carried out by the relevant DEG member. Upon comparison of the initial and final price offers transmitted by the vendor company and entered into the system, the offer approved by a majority vote of the DEG members is accepted. Approval takes place through the system.

\subsection{Stage 6: Announcement of the Decision}

\subsubsection{A Consortial Deal}

The license agreement of the product for which a positive decision has been taken at the end of the evaluation process is sent to the ANKOS License Agreements Group (LAG) for a final detailed review. The price offer on which the agreement is reached by approval of DEG and LAG is announced through the ANKOS mailing list.

\subsubsection{The Consortial Deal may not be Formed}

When a negative decision is taken, ANKOS members and the vendor company are informed, complete with justifications, that a deal may not be formed. In the case of a decision not to form a consortial deal, the last price negotiated and the contact details of the publisher/agent are transmitted through the ANKOS mailing list for those members who may want to acquire an individual subscription to the product themselves.

While designing the e-resource evaluation process, multiple checks were carried out. The stages established in this respect have played an important role in the efficient and effective evaluation of e-resources, and the idea emerged to create an online evaluation environment in order to provide a standardization of the management of the process and to achieve a systematic approach. With this in mind, work began on the formation of the PAS, which will be described in detail in the following section.

\section{Publisher Application System}

\subsection{Why the Need for a System?}

Before the creation of the system, the evaluation process used to be carried out by the ANKOS DEG members through the use of e-mail. This enabled all of the acquired information to be shared but did not allow for the storage of the collected documents in a single, common space. Disruptions could occur in the information flow due either to the group members leaving the group or being away from the evaluation process for various reasons. Furthermore, disruptions could also occur in the sharing of evaluation information among group members - all of which sometimes resulted in difficulties in compiling past information, in obtaining statistical information, and in the overall assessment of the point reached in the evaluation process. Publishers and vendors became uncertain as to where or to whom they would submit their offers and there were occasions when deadlines expired for feedback. All the feedback pointed to the need for a professional system, both for parties wishing to introduce their new products to ANKOS and for those in ANKOS engaged in the evaluation of e-resources. The introduction of PAS had the following aims:

- To improve the evaluation process

- To provide standardization in the evaluation process in the submission of documents required during new product applications by publishers/agents and for the decision-making process

- To provide a data storage repository for products, publishers/agents, and price proposals

- To enable an efficient and equitable share of resources

- To place decisions related to the evaluation and decision-making process on record so that transparency and reliability are ensured

- To achieve the integration of processes and systems within ANKOS

- To lighten the workload of the DEG members.

\subsection{How the System was Formed}

Members of the DEG started to communicate their observations during the group's annual meetings. These meetings served to voice the conditions necessitating the existence of a system and expectations from it. Problems encountered and suggestions for a solution were put together to lay down the basic parameters of a system. Then the planning stage began.

Initial work on the system, which was planned to consist of two separate interfaces, focused on the interface for the publishers or agents. This interface was designed as a form wherein publishers or agents trying to present their products to ANKOS could enter all details pertaining to their products. The layout of the form, its content, main titles of the fields, and the information to be required under those main titles were designed in the course of a period of 8 months. Upon completion, the beta version of the Publisher Application Form (PAF), constituting the first interface of the Publisher Application System and containing 5 main titles, was placed on the ANKOS Web site in June 2010. The first entry into the system took place in August 2010. Later, the PAS was updated and improved in line with feedback received from publishers and agents. Present in its current form on the ANKOS Web site and used actively, the form undergoes constant development and updating per feedback received and update requirements detected.

\subsubsection{Features of PAF, the first Interface of the PAS}

Features of PAF include the following:

- Designed in open source Linux platform through PHP (Hypertext Preprocessor) coding on a MySQL database.

- A bilingual interface in Turkish and English. With a view to making them easy to remember, the system's Web addresses operate on the following subdomains: http://publisher.ankos.gen.tr for the English language interface and http://yayinci.ankos.gen.tr for the Turkish language interface. Language selection is triggered automatically and is based on the subdomain selected.

- In order to prevent spam, a reCAPTCHA (http://www.google.com/ recaptcha) anti-bot feature, provided free of charge by Google, is used.

- An information screen aimed at publishers and agents, who will fill in the form, welcomes the users before the actual form screen. Useful tips for filling in the form and important points to be taken into account are provided in this informative text.

- Publishers and agents are allowed to upload files. When the ATTACHMENT button on the form is clicked, a file uploading wizard is activated and the user is asked to select a file to upload. Multiple file selection is possible by the use of a CTRL key. The file format extensions permitted are as follows: jpg, png, gif, txt, zip, rar, pdf, doc, docx, xls, and xlsx. Users may see the progress and completion of uploading their selected file(s) and may cancel the operation by hitting the $\mathrm{X}$ button if necessary. In case there is another file of the same name, the system will alert the user that a file of identical name is already stored in the system and ask whether the user wishes to replace the old file with the new one. However, as the date of 
application is automatically appended to the file names as a prefix, the possibility of a file of identical name being uploaded is extremely slim. The name of the uploaded file will appear in the relevant line, to the left of which an EXPLANATION related to the file may be entered. Individual explanation boxes are provided for each file uploaded. File uploading operations are carried out by the use of Uplodify (http://www.uploadify.com/) script coded with AJAX (Asynchronous JavaScript) on the form page.

- Completion of the form is concluded by clicking the SAVE button. If the form is saved successfully, the user will be redirected to the screen shown below - five seconds after which the user will be taken to http://www.ankos.gen.tr/en, and the application will be transmitted to the DEG members by e-mail.

To ensure high performance and for security purposes, PAS is being hosted on a VDS (Virtual Dedicated Server) belonging to ANKOS. The form is open for use by everyone and placed in the ANKOS Web site to allow easy access (Figure 2). Care has been taken in the design of the form so that its content provides a reference as well for those ANKOS members that will perform an institutional evaluation for different products. By reviewing the titles in the form, institutions may perform their evaluation of the products proposed to them on an institution-level outside of ANKOS by publishers and agents.

After the entering of products into the system, the second interface begins. This is designed to enable the DEG members to evaluate the products entered into the system.

\subsubsection{Features of DEG Electronic Evaluation Area, the Second Interface of} the PAS

- As all applications are displayed in the DEG interface, extra security measures were taken on the server side. The user name and password are needed for logging in.

- The DEG member who correctly types in their 'username' and 'password' is directed to the Application List. This list can be sorted alphabetically by product name or application date ( $\mathrm{A}-\mathrm{Z}$ or $\mathrm{Z}-\mathrm{A})$. The product name appearing in the list can be clicked on to display details. The 'Edit User Information' link placed at the top of this page can be used for each DEG member to update his or her personal information and password on his or her personal page.

- The lower part of the form lists the files uploaded by the person who filled in the form, complete with explanations, which takes the user to the content of the relevant file if clicked.

- In the comments section, each DEG member may do the following: o write a comment,

o upload a file to accompany a comment she or he wrote,

o edit and/or delete comments,

o name, date, and time are automatically appended to the entered comments,

o edit and delete buttons appear only on a member's own comment page.

- All comments entered here are automatically e-mailed to all DEG member addresses. In the body of the e-mails sent, comments appear in chronological order, starting with the latest comment. This e-mail also incorporates a quick link (URL) to the system.

- The products entered here may be sorted alphabetically or by date.

- The following information may be added and displayed on the form included within the DEG interface:

o the relevant Steering Committee and DEG member and the relevant Database Liaison,

o dates of trial access,

o the current status of the evaluation.

- The list of the applications included in the DEG interface may be exported into and displayed in Excel, complete with the current status (Figure 3).

\section{Conclusion and Evaluation}

In 2010 when the system was launched, a total of 163 databases were evaluated. Negotiations for 95 databases were concluded, whereby

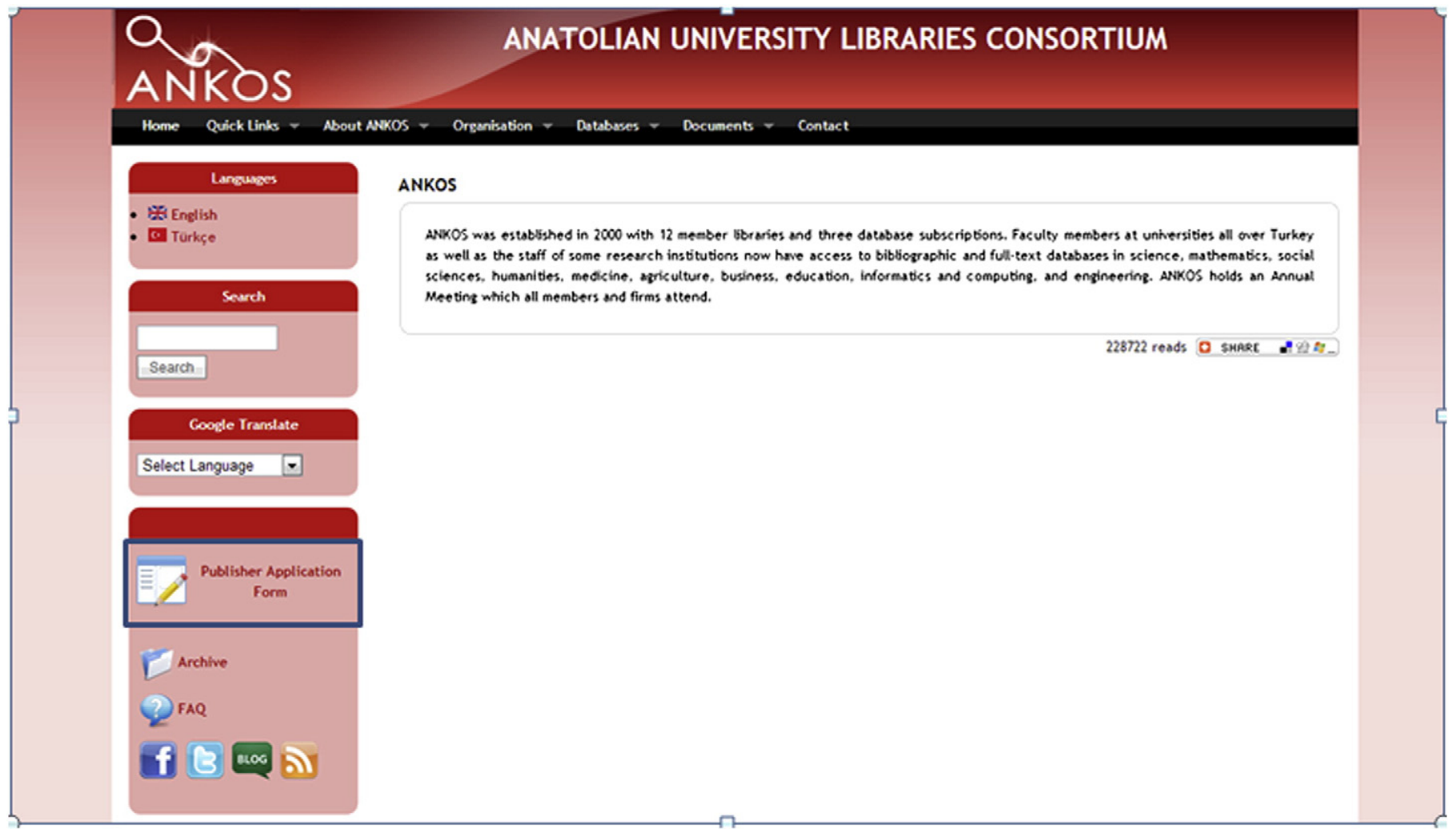

Figure 2. Publisher application form. 
it was decided not to consider 40 of those within the consortium and to evaluate 28 within the following year.

In 2011, price negotiations for 29 databases were concluded, and it was decided not to consider 7 of those within the consortium and to evaluate 29 within the following year.

This system has provided added value to ANKOS and its members, having enhanced the database evaluation process.

In this context, the following section briefly describes the impact of the PAS on the e-resource evaluation process.

\subsection{Formation of a Data Pool}

While the PAS was being designed, one of the more important objectives was the ability to archive the information of the evaluated products, of the publishers and agents submitting the proposals, and the price information received for the same product in different years.

\subsubsection{Evaluated Product}

Archiving of all products regardless of whether or not they are eventually included in the consortium is important, in the sense of both having a profile of ANKOS products obtained and of having the products categorized according to their evaluation results.

\subsubsection{Publishers/Agents Submitting Offers}

In order to obtain a map of companies already having a product within the consortium or wishing to be a part of the consortium with a product, it is important to place companies serving in this field on record and to archive their information.

\subsubsection{Price Proposals Submitted}

Price proposals submitted to the consortium may exhibit a variation based on the social and economic changes experienced in Turkey and worldwide. Different prices are submitted in different times, and price proposals are reviewed and re-entered into the system on the basis of evaluations performed by the DEG members. Archiving all of the old, new, and updated price proposals is instrumental in measuring the effectiveness of the group's evaluation process and helps in the development of new pricing models.

\subsection{Ensuring Standardization}

It is the primary duty of ANKOS volunteers to perform the duties assigned to them by their respective institutions. This fact brought about the inevitable adoption of a systematic approach in order to make efficient use of manpower and made the establishment of

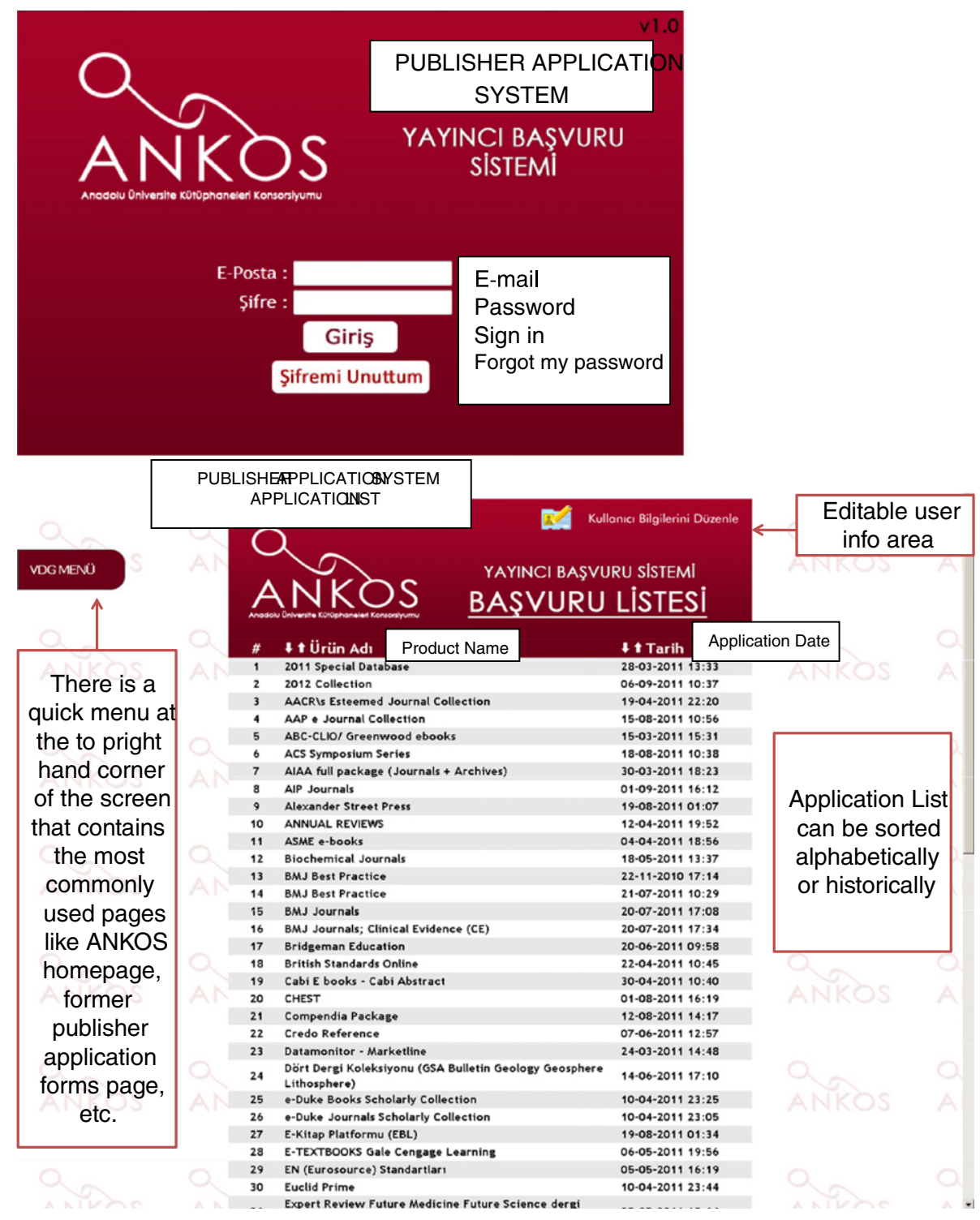

Figure 3. DEG interface. 


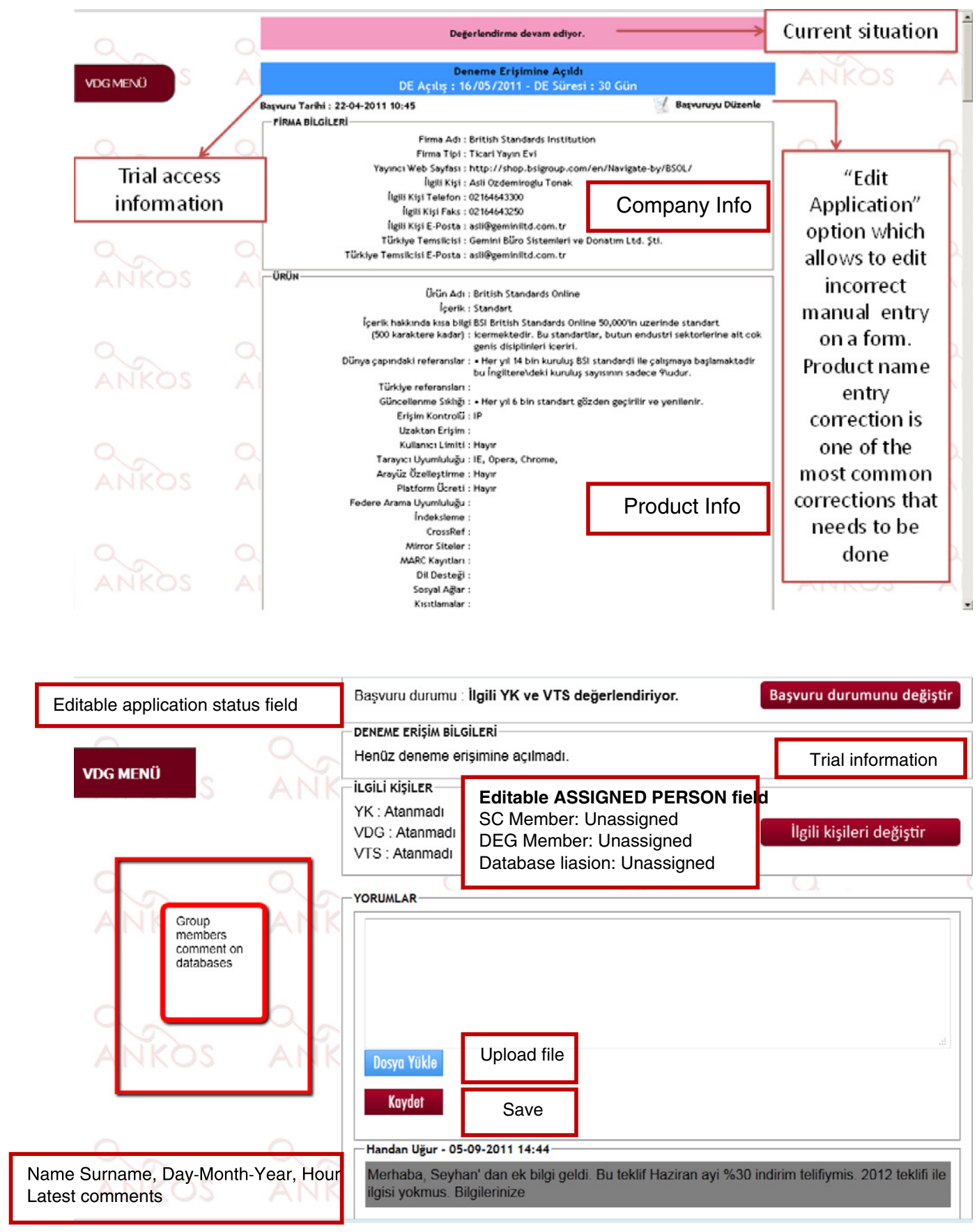

Figure 3 (continued).

standards to enhance information sharing and communication between relevant groups a definite requirement.

\subsubsection{The Process}

Standardizing and automating work processes are important to increase the group's performance and to allow it to take more effective and correct decisions. The standardization of processes is a high priority requirement to enable the tracking of work by way of a certain tool and forms the basis of PAS.

\subsubsection{Documents}

Requirement of product documentation of the same quality and quantity received from all publishers and agents provides equal conditions for all parties submitting offers as well as mass acquisition of all the information forming the basis of evaluation in a single go, which accelerates the evaluation process.

\subsection{Recording of Evaluations}

All evaluations carried out through the system are visible to the Steering Committee as well as the DEG members allowing monitoring of all stages. The fact that all information entered into the system is archived and the decisions taken are placed on record enables a transparent, accountable, and reliable process.

\subsection{Achieving an Interactive Working Environment}

The system allows group members, who communicate during the evaluation process with different groups/persons inside and outside 
of the consortium, to interact with Database Liaisons and with members of LAG and the Steering Committee. Where multiple evaluation mechanisms are essential, the group benefits from the automated information flow, which allows real-time follow up of the developments in the evaluation process along with all involved parties, immediate intervention in case of problems, and swift conclusion of the process.

\subsection{Integrated Operation}

With its ever increasing number of members and products, ANKOS designs and implements proprietary decision support systems to turn any possible disadvantages of such fast-paced growth into advantage. The objective of any new tool is determined as fulfilling its intended function by creating subsystems that will work in harmony with one another to form a single, integrated system to help manage the work processes. As of today, the most important objective in connection with the PAS is to integrate it with the ANKOS's electronic resource management system (ERMS). Assessment meetings to this end continue.

As the above content indicates, the PAS is a system designed to help in the evaluation of the products intended for addition into the consortium. Capable of Web-based archiving and online evaluation, this tool has increased the efficiency and effectiveness of the DEG, and the standardization made possible the workflow of the group.

Once launched for active use, the system allowed the creation of an information pool, enabled the group members to efficiently and productively use their time, and made a more detailed evaluation of products possible. The PAS is still developing and aims to provide solutions to problems encountered in the evaluation process. In this respect, it is clear that the system is not static but of a dynamic nature. Its first version having been launched by the DEG, the development of new versions of the PAS that would work in integration with the ERMS will constitute a major achievement in the design of a fundamental decision support system for ANKOS.

\section{References}

Akbaytürk, T. (2003a). The impact of consortial purchasing on library acquisitions: The Turkish experience. Paper presented at the 24th IATUL Annual Conference, Ankara, Turkey (Retrieved from http://eprints.rclis.org/handle/10760/8450\#references)

Akbaytürk, T. (2003b). Türkiye'deki konsorsiyumların kütüphanelerde satın alma üzerine etkisi. Türk Kütüphaneciliği, 17(3), 247-262.

Cimen, E., Tuglu, A., Manyas, M., Celikbas, S., \& Celikbas, Z. (2009). New approaches for interlibrary loan operations in Turkey: KITS (Interlibrary Loan Tracking System). Paper presented at the World Library and Information Congress: 75th IFLA General Conference and Assembly, Milan, Italy Retrieved from http://conference.ifla.org/past/ ifla75/143-cimen-en.pdf

Cukadar, S., Tuglu, A., \& Gurdal, G. (2012). New electronic resources management system for the ANKOS Consortium. Journal of Academic of Librarianship. http://dx.doi.org/10. 1016/j.acalib.2012.11.011.

Erdogan, P. L. (2009). Portrait of a consortium: ANKOS (Anatolian University Libraries Consortium). Journal of Academic of Librarianship, 35(4), 377-385.

Erdogan, P. L., \& Karasozen, B. (2006). ANKOS and its dealings with vendors. Journal of Library Administration, 44(3-4), 69-83.

Karasözen, B. (2002). Kütüphane hizmetlerinde işbirliği ve ortaklıklar: ANKOS. Presented at Elektronik Gelismeler Isı̆ğında Araștırma Kütüphaneleri Sempozyumu, Bolu, Turkey (Retrieved from http://www.ankos.gen.tr/belgeler/kutuphane-hizmetlerinde-isbirligive-ortakliklar-ankos-233)

Karasozen, B., Kaygusuz, A., \& Ozen, H. (2007). Patterns of e-journal usage within the Anatolian University Library Consortium. Serials: The Journal for the Serials Community, 20(1), 37-42.

Karasozen, B., \& Lindley, J. (2004). The impact of ANKOS: Consortium development in Turkey. Journal of Academic of Librarianship, 30, 402-409.

Lindley, J. (2004). The Turkish National Site License (TRNLS). Serials: The Journal for the Serials Community, 16(2), 187-190.

Özen, H. (2007). Elektronik dergilerde kullanım analizi: ODTÜ ve ANKOS örneği. [PowerPoint slides]. Paper presented at Değișen Dünyada Bilgi Yönetimi Sempozyumu, Ankara, Turkey (Retrieved at http://by2007.bilgiyonetimi.net/bildiriler/ozen-ppt.pdf)

Toplu, M. (2009). Elektronik yayıncilığın ortak koleksiyon gelistirme ve kütüphane konsorsiyumlarına etkileri ve Türkiye'deki uygulamalar. Türk Kütüphaneciliği, 23(3), $448-488$.

http://www.ankos.gen.tr/en/genel/management-205. 
Copyright of Serials Review is the property of Routledge and its content may not be copied or emailed to multiple sites or posted to a listserv without the copyright holder's express written permission. However, users may print, download, or email articles for individual use. 